DOI 10.37882/2223-2982.2021.04.28

\title{
МОРАЛЬНО-ПСИХОЛОГИЧЕСКИЙ ОБЛИК ВОЕННОСЛУЖАЩЕГО АРМИИ США В ВОЕННО-ПАТРИОТИЧЕСКОМ КИНО (НА МАТЕРИАЛЕ АНГЛИЙСКОГО ЯЗЫКА)
}

\section{THE MORAL AND PSYCHOLOGICAL IMAGE OF THE AMERICAN GI REFLECTED BY MILITARY PATRIOTIC CINEMA (AS EXEMPLIFIED IN ENGLISH)}

\section{A. Romanov \\ I. Balkanov}

Summary:This article focuses on military stereotypes broadcast through the U.S. national war movie. Military film discourse is regarded as a media environment that contributes to a positive field of meanings about the U.S. Armed Forces and its service members. An overwhelming majority of military pictures addressed to the general public has a patriotic modality. The object of the research is the U.S. military cluster system of values reflected by social stereotypes. The subject area of scientific research is Gl's moral image mirrored by military and patriotic films. Illustrative material is drawn based on continuous sampling of relevant illustrations from 11 war films on World War II, the Vietnam conflict, the Persian Gulf War, the armed conflict in Somalia, the wars in Afghanistan and in Iraq.

Keywords: U.S. Armed Forces, military subculture, film discourse, stereotyping, axiosphere, system of values, $\mathrm{Gl}$.
Романов Александр Сергеевич

К.филол.н., дочент, ФГКВОУ ВО «Военный университет» Министерства обороны Российской Федерации research2021@mail.ru

Балканов Илья Владимирович

К.филол.н., дочент, ФГКВОУ ВО «Военный университет» Министерства обороны Российской Федерации

Аннотация: Настоящая статья посвящена исследованию милитарных стереотипов, транслируемых через художественные произведения национального кинематографа США. Военный кинодискурс понимается как медийная среда, способствующая формированию положительного поля смыслов 06 американской армии и ее военнослужащих. Подавляющее число военных кинолент, адресованных широкой общественности, имеют патриотическую модальность. Объект научного исследования - система ценностей армейского кластера американской лингвокультуры сквозь призму социального стереотипа. Предметную область научного исследования составляет моральный облик американского военнослужащего в зеркале художественных военно-патриотических кинолент. Иллюстративный материал извлекается методом сплошной выборки релевантных фрагментов из 11 кинолент, посвященных Второй мировой войне, вьетнамскому конфликту, первой военной кампании в Персидском заливе, вооруженному конфликту в Сомали, войнам в Афганистане и в Ираке.

Ключевые слова: вооруженные силы США, армейская субкультура, кинодискурс, стереотипизация, аксиосфера, система ценностей, $\mathrm{Gl}$.
$\Pi$ родукты массового интеллектуального потребления американской «фабрики грез» рассматриваются с точки зрения информационно-психологического воздействия на массового адресата через апелляцию к социальному мифу. Военный кинодискурс интерпретируется прежде всего как манипулятивная медийная среда глобального охвата целевой аудитории. Кинодискурс милитарной направленности способствует формированию и закреплению стереотипов об американской армии. В США национальный кинематограф преимущественно патриотичен, нацелен на формирование положительного корпоративного имиджа вооруженных сил. Важное свойство военного кино - экспликация не только авто- и гетеростереотипов, но и системы ценностей воинской среды, вербализованной в знаках языка и культуры. В качестве объекта научного исследования выступает аксиосфера американского воинства, осмысленная через стереотипы коллективного языкового сознания носителей амери- канской лингвокультуры. Предметная область исследования - референтный морально-психологический облик $\mathrm{Gl}^{1}$ в военно-патриотических фильмах национального кинематографа. Абстрактная номинация Gl синонимична собирательному образу типичного представителя военного социума США. Акцент предпринятого исследования сделан на базовых ценностях армейской субкультуры. Совокупный корпус проанализированного материала представлен 11 художественными кинолентами, посвященными Второй мировой войне (1941-1945 гг.), войне во Вьетнаме (1965-1973 гг.), войне в Персидском заливе (1990-1991 гг.), вооруженному конфликту в Сомали (1993 г.), войнам в Афганистане (2001-н. вр.) и в Ираке (2003-н. вр.). В общей сложности проанализировано около 25 часов звучащей речи. Перечень изученных кинолент приведен в таблице.

В своем содержательном плане художественные ки-

В нашем исследовании аббревиатура GI трактуется широко и выступает родовым понятием по отношению к узко специальным лексемам soldier, sailor, marine, airman, coast guardsman, guardian (Space Force service member), обозначающим принадлежность к определенному виду вооруженных сил армии США. 


\begin{tabular}{|l|l|c|c|c|}
\hline \multicolumn{5}{|c|}{ Фильмография исследования } \\
\hline \multirow{2}{*}{ Вооруженный конфликт } & \multicolumn{1}{|c|}{ Название картины } & $\begin{array}{c}\text { Год выхода } \\
\text { в прокат }\end{array}$ & Продолжительность & Режиссер \\
\hline \multirow{2}{*}{$\begin{array}{l}\text { World War II } \\
\text { (1941-1945) }\end{array}$} & Saving Private Ryan & 1998 & $169 \mathrm{~min}$. & S. Spielberg \\
\cline { 2 - 5 } & Hacksaw Ridge & 2016 & $139 \mathrm{~min}$. & M. Gibson \\
\hline \multirow{3}{*}{$\begin{array}{l}\text { Vietnam War } \\
\text { (1965-1973) }\end{array}$} & Apocalypse Now & 1979 & $153 \mathrm{~min}$. & F.F. Coppola \\
\cline { 2 - 5 } & Born on the 4th of July & 1989 & $145 \mathrm{~min}$. & 0. Stone \\
\cline { 2 - 5 } & We were Soldiers & 2002 & $138 \mathrm{~min}$. & M. Gibson \\
\hline The Gulf War (1990-1991) & Jarhead & 2005 & $123 \mathrm{~min}$. & S. Mendes \\
\hline Somalia conflict (1993) & Black Hawk Down & 2001 & $144 \mathrm{~min}$. & R. Scott \\
\hline \multirow{2}{*}{$\begin{array}{l}\text { War in Afghanistan } \\
\text { (2001-H. Bр.) }\end{array}$} & Lone Survivor & 2013 & $121 \mathrm{~min}$. & M. Luttrell, P. Robinson \\
\cline { 2 - 5 } & The Hurt Locker & 2008 & $138 \mathrm{~min}$. & K. Bigelow \\
\hline $\begin{array}{l}\text { War in Iraq } \\
\text { (2003-H. Bр.) }\end{array}$ & American Sniper & 2014 & $132 \mathrm{~min}$. & C. Eastwood \\
\cline { 2 - 5 } & Act of Valour & 2012 & $111 \mathrm{~min}$. & M. McCoy, S. Waugh \\
\hline
\end{tabular}

ноленты о войне могут быть условно поделены на две категории: военно-патриотические и антивоенные. Положительный киноимидж вооруженных сил США искусственно создаваемый конструкт, отвечающий потребностям консолидации общества, его милитаризации и непрерывного доукомплектования войск. В картинах, возвеличивающих военную мощь США в глобальном сознании не только американской, но и международной общественности, доминирующим прагматическим вектором выступает положительный нарратив. Последний связан с героизацией собирательного образа Gl. Американский солдат неизменно предстает перед целевой аудиторией в амплуа патриота доброй воли, миротвориа, поборника американского образа жизни, демократических иенностей, свобод и идеалов, бориа с религиозным экстремизмом (но не Исламом как религиозной конфессией).

Подавляющее большинство военных кинолент имеют патриотическое содержание и ставят целью возведение Gl на пьедестал социального почета. В национальной кинематографии военнослужащий воплощает образ идеального гражданина, истинного патриота и бдительного стража нации. Голливудское кино - один из товаров массового интеллектуального потребления. Кинематограф в полной мере отвечает потребностям мобилизации американского социума в интересах поддержания боеспособности «военной машины» Пентагона. Патриотические фильмы нацелены на легитимизацию милитаризма и обоснование социального мифа о национальной исключительности США. Военные киноленты - своего рода «идеологические бастионы», стоящие на страже героического прошлого или настоящего. В художественных картинах, посвященных событиям Второй мировой войны, отображен мир отцов-основателей, мир первых и лучших. В качестве классической иллюстрации послужат эпическая военная драма С. Спилберга «Спасти рядового Райана» (Saving Private Ryan (1998)), военная мелодрама М. Бэя «Перл-Харбор» (Pearl Harbour (2001)), военные драмы Г. Хоблита «Война Харта» (Hart's War (2002)), А. Фукуа «Слезы солнца» (Tears of the Sun (2003)), К. Иствуда «Флаги наших отцов» (Flags of Our Fathers (2006)), М. Гибсона «По соображениям совести» (Hacksaw Ridge (2016)) и др.

Одним из ключевых акцентов патриотического кино выступает сема элитарности «воинской касты». Служба интересам отечества - удел настоящих мужчин, посвятивших свои жизни высшей цели. В кино широко тиражируется идея сопричастности Gl к важным историческим событиям, формирующим облик дня сегодняшнего. Иными словами, служба в армии позволяет прожить «жизнь подлинную», ощутить себя частью чего-то по-настоящему значимого. Подкрепим изложенную мысль фрагментом из фильма Born on the 4th of July (1989).

- "No, you're crazy." "Our dads got to go to WWII. This is our chance to do something... to be part of history, guys." "Yeah, just like our dads." - «Нет, ты безумец. Наши отцы воевали во Второй мировой войне. Это наш шанс сделать что-то... войти в историю, парни. - Точно, прямо как наши отцы» [8, 00:16:29$00: 16: 35]^{2}$.

Красной линией в военно-патриотическом кино проходит идея национальной исключительности. В военных фильмах, основанных на идеологии правого дела, реципиент преклоняется перед мужеством, благородством, воинской доблестью и высоким профессионализмом американского воина. Аксиосфера армейской субкультуры Gl вбирает в себя такие ценности, как честь, преданность, сплоченность, решительность, сдержанность,

2 Здесь и далее по тексту перевод наш - Романов А.С., Балканов И.В. Ссылки на иллюстративный материал сопровождаются указанием временного интервала приводимых фрагментов. 
дисциплинированность, наличие боевого опыта [9], [16, p. 68]. Названные аксиологические ориентиры запечатлены в девизе "We leave no man behind" - «Мы своих не бросаем». Девиз составляет основу морально-этического кодекса американского воинства. Сплоченность коллектива в условиях боевых действий - важнейший из приоритетов воинской службы. Дух товарищества находит выражение в готовности доверить свою жизнь собрату по оружию. «Коллективный разум» отвечает интересам выполнения поставленной задачи и выживаемости в бою [13, р. 21]. Ментальность боевого товарищества проявляется в чувстве коллективизма. Социальная когезия и примат интересов воинского коллектива противопоставлены индивидуализму, эгоистическим наклонностям. Подкрепим сказанное иллюстративным материалом из киноленты Black Hawk Down (2001). На вопрос о мотивах, побуждающих военного человека всякий раз возвращаться на войну, рискуя собственной жизнью, боец элитного подразделения СВ США Delta Force отвечает:

- "When I go home people would ask me: "Hey, Hoot, why do you do it, man? What, you some kinda war junkie?" You know what I'll say? I won't say a goddamn word. Why? They won't understand. They won't understand why we do it. They won't understand that it's about the men next to you, and that's it. That's all it is." - "Дома часто спрашивают меня: «Сова ${ }^{3}$, зачем это все, зачем? Ты без войны уже не можешь?» Я им ни черта не отвечаю. Чего ради? Им не понять. Им не понять все это. Не понять, что рядом с тобой погибали друзья. Вот и все. Очень просто» [7, 02:11:4602:12:34]. Ср. также:

- "A friend of mine asked me <...>: "Why do you need this someone else's war? Do you consider yourself heroes?" Back then I had no answer. Today I would say no. One can't be a hero in hell." - «Один мой приятель спросил меня <...>: «Зачем вам эта чужая война? Вы считаете себя героями?» Тогда я не знал, что ответить. Теперь бы я ответил нет, не считаю. В аду нельзя быть героем» [lbid., 02:13:34 - 02:14:02].

Семы жертвенности, опасности воинского служения и добровольного самоотречения во имя высоких идеалов отчетливо прослеживаются на примере следующих фрагментов из военных кинофильмов The Hurt Locker (2008), Lone Survivor (2013) и American Sniper (2014). Ср.:

- "At least I'll die in the line of duty, proud and strong." «По крайней мере я погибну гордым и сильным, исполняя свой воинский долг» [17, 00:45:34]; “Every time we go out, it's life or death. You roll the dice" «Всякий раз, когда мы идем на задание, речь идет о жизни или смерти. Это игра в рулетку» [lbid., 01:59:40].

- "You can die for your country. I'm going to live for mine." - «Ты можешь умереть за свою страну. Я же собираюсь жить во имя своей» [12, 01:11:37].

- "Wait, why would you say I'm self-centered? I'd lay down my life for my country." "Why?" "It's the greatest country on Earth. I'd do everything I can to protect it." - «Погоди, с чего это ты взяла, что я эгоистичен? Я готов пожертвовать жизнью ради своей страны. - Ради чего? - Это величайшая страна на Земле. Я сделаю все возможное, чтобы защитить ее» [5, 00:16:07].

В медийно опосредованном облике Gl запечатлены социальные стереотипы массового обыденного сознания. В американских художественных кинолентах вооруженные силы США представлены как основная ячейка общества, сплочённая узами родства. Лексемы и словосочетания bro, soulmate, warbody, brothers and sisters in arms, band of brothers отражают семы духовного единения боевого товарищества, прошедшего крещение огнём. Для армейской субкультуры характерны в высшей степени доверительные, поистине родственные отношения. Эта духовная связь, известная как феномен «братских уз», формируется под влиянием сильного стресса. Проанализируем эпизоды из кинолент [Saving Private Ryan (1998) и Act of Valour (2012).

- "It's <...> about the bonds of brotherhood that develop between soldiers during war." - «Речь идет о братских узах, крепнущих между военнослужащих на поле боя» [15, 00:42:47-00:42:50];

- "There was a brotherhood between us, and we depended on each other more than a family" - «Мы были связаны узами братства и зависели друг от друга больше, чем члены одной семьи» [4, 00:09:13].

Один из участников сетевого форума Usmilitariaforum.com предложил собственную классификацию наиболее распространенных в американском кино типажей Gl. Преломленная сквозь призму стереотипа «типичная американская рота» представлена кинообразами «Южанина» («Техасского ковбоя» / «Фермера»), «Парня из большого города», «Тихони», «Свирепого сержанта», «Ковальского». Остановимся на каждом из перечисленных архетипов.

Образ «Техасского ковбоя» (the Texan cowboy), олицетворяющего мятежный дух нации, ассоциируется прежде всего с прославленными воинскими традициями юга. У парня из Техаса ярко выраженный южный акцент, он любит играть на губной гармошке, пробуждающей ностальгические чувства и тоску по отчему дому. В американских военных фильмах главный персонаж нередко является уроженцем южных штатов (см., например, картины Lone Survivor, American Sniper и др.) и тому есть логическое обоснование. Дело в том, что вооруженные силы США комплектуются преимущественно выходцами

3 В приводимом фрагменте речь идет о прозвище бойца (от англ. сущ. hoot- совиный крик). 
из южных штатов, в то время как северо-восток страны «поставляет» В войска наименьший процент рекрутовновобранцев [13, p. 21], [14, p. 5]. Ср.:

Кинотипаж «Фермера» (the Southern farm boy) ассоциируется с кротким нравом, скромностью, привязанностью к семейному очагу. В подкладке головного убора парень из южной глубинки хранит фотографию любимой.

В сознании американской целевой аудитории кинотипаж «Парня из большого города» (the Streetwise hustler) репрезентирован как предприимчивый делец, воспитанный по законам улиц. Как правило, это говорящий скороговоркой житель Нью-Йорка. Этот человек способен раздобыть все, что угодно (от банки мясного фарша «Спам» до бутылки скотча), однако лишь в том случае, если вы сойдетесь в цене!

В американском языковом сознания кинотипаж «Тихони» (the Quiet one) наделен совокупностью положительных качеств: высоким уровнем интеллекта, человечностью, дисциплинированностью, проницательностью. Личное время «Тихоня» предпочитает проводить за чтением литературы, по окончании контракта мечтает о профессии юриста.

Кинообраз «Свирепого сержанта» (the Hard-bitten NCO) олицетворяет референтный образ строевого командира. За долгие годы действительной военной службы старый вояка повидал немало. Несмотря на крутость нрава и требовательность к подчиненным, пользуется уважением личного состава. Имеет пагубное пристрастие к алкоголю, который помогает ему забыться.

Кинотипаж «Ковальского» (Kowalski). В американских военных кинолентах всегда фигурирует парень по фамилии Ковальский! [3, с. 175-177].

Война, утверждал Августин Блаженный, по своей сути есть зло. Однако в том случае, если война ведется во имя христианской веры, она становится злом необходимым, продуктом божественного предопределения. По мысли христианского богослова и философа эпохи Средневековья, заповедь «не убий» « <...> отнюдь не преступают те, которые ведут войны по полномочию от Бога» $[1$, с. 119]. Невзирая на то, что в профессиональной среде Gl отношение к религии сугубо индивидуально, военный социум в целом характеризуется религиозностью. В каждом воинском формировании по штату предусмотрен капеллан, ведущий духовную работу с личным составом. Принято различать, например, Chaplain Corps - Christian Faith (служба военных священников (католики и протестанты)), Chaplain Corps - Jewish Faith (служба военных священников (иудеи)), Chaplain Corps Buddhist Faith (служба военных священников (будди- сты)), Chaplain Corps - Muslim Faith (служба военных священников (мусульмане)).

Постулаты богоизбранности отчетливо прослеживаются в текстах национального гимна США The Star-Spangled Banner - The National Anthem ("Then conquer we must, when our cause it is just-/And this be our motto: "In God is our Trust"), воинской присяги Oath of Enlistment ("So help me God"), Кодекса поведения американского военнослужащего Code of Conduct ("I will trust in my God and in the United States of America"), Клятвы верности государственному флагу США Pledge of Allegiance ("I pledge the allegiance to the Flag of the United States of America, / And to the Republic for which it stands: Our Nation, under God, Indivisible, with liberty and justice for all"), профессиональных кредо ("before God I swear this confession").

Военные киноленты несут идеологический заряд. Священное писание всегда находилось на службе идеологов США в обоснование идеи национальной исключительности. В сознании целевой аудитории собирательный образ Gl воплощает христианские ценности. Огнем и мечом американский крестоносец вершит суд Божий во имя процветания нации. На полях военного кинодискурса англо-саксонское мессианство представлено ярко, о чем свидетельствуют следующие примеры. Обратимся к кинолентам Apocalypse Now (1979), We were Soldiers (2002), Jarhead (2005), American Sniper (2014).

- "Everyone gets everything he wants. I wanted a mission, and for my sins, they gave me one <...>." - «Каждый из нас получает то, чего желает. Мне хотелось попасть на задание, и за мои грехи я его получил» [6, 00:07:40-00:07:46];

- "Our Father in heaven, before we go into battle, every soldier among us will approach you, each in his own way. <...> I pray you watch over the young men, like Jack Geoghegan, that I lead into battle. You use me as your instrument in this awful hell of war to watch over them." - «Отец наш небесный, уходя в бой, каждый солдат обратится к тебе, каждый сделает это посвоему. <...> Я прошу, позаботься о таких ребятах, как Джэк Геган, которых я поведу в бой. Ты сделал меня своим орудием, чтобы сберечь их на войне» [18, 00:23:44-00:24:14];

- "Jihad is the way of all Arab people. We are now Operation Desert Storm. And we're the fucking righteous hammer of God." - "Все арабское население вступило на путь джихада. С этого момента мы - участники операции «Буря в пустыне». И мы, черт возьми, карающая десница Господа» [11, 01:09:56-01:10:03];

- "I want you to put the fear of God into these savages..." - «Хочу, чтоб ты вселил страх Господень в этих дикарей...» [5, 00:59:45]. "That Bible of yours, is that bulletproof?" "What, the one I put in here?" "Yeah, I just never saw you open it. I assumed..." "God, country, 
family, right?" - «Твоя Библия, она пуленепробиваемая? - Какая, которую я сюда положил? - Она самая. Ни разу не видел, чтобы ты ее открывал. Вот и подумал... - За Бога, Отчизну, семью, верно?» [lbid.: 01:00:09-01:00:52].

Военные киноленты выполняют культурно-мировоззренческую функцию, оказывают значительное влияние на формирование имиджа вооруженных сил США. Рассчитанные не только на внутреннего, но и внешнего потребителя американские картины о войне отвечают потребностям мобилизации общественности, поддержания высокого престижа военной службы, легитимизации милитаризма. По образному выражению Е.А. Евтушенко, «пропаганда всегда была смазочным маслом военной машины» [2, с. 303]. На основании проведенного анализа делается вывод о том, что военные художественные произведения американского кинематографа позволяют запечатлеть:

1. реалии военной службы конкретного исторического периода;

2. систему аксиологических ориентиров армейской субкультурной среды;

3. особенности речевого поведения собирательного образа Gl, реализованного в официальном и неформальном регистрах армейского идиома;

4. социальные мифы о профессиональной группе военнослужащих, эксплицированные в знаках языка и культуры;

5. прагматический вектор воздействия на целевую аудиторию и др. аспекты.

\section{ЛИТЕРАТУРА}

1. Блаж. Августин. Творения. Киев, 1910. Ч. 6. С. 119.

2. Евтушенко Е.А. Точка опоры / Е.А. Евтушенко. М.: Молодая гвардия, 1981. 303 С.

3. Романов А.С. Этнические стереотипы армейской субкультурной среды США в знаках языка и культуры: монография / А.С. Романов. М.: Военный университет, 2017. $231 \mathrm{c}$.

4. Act of Valour (action film; 111 min.) / M. McCoy, S. Waugh, 2012.

5. American Sniper (historical war drama; 132 min.) / C. Eastwood, 2014.

6. Apocalypse Now (drama anti-war film; 153 min.) / F.F. Coppola, 1979.

7. Black Hawk Down (historical war drama; 144 min.) / R. Scott, 2001.

8. Born on the 4th of July (anti-war drama film; 145 min.) / 0. Stone, 1989.

9. Exum H., Coll J.E., \& Weiss E.L. A Civilian Counselor's Primer for Counseling Veterans, 2nd edition / H. Exum, J. E. Coll, \& E. L. Weiss. Deerpark, NY: Linus Publications, Inc., 2011. 202 p.

10. Hacksaw Ridge (biographical war drama film; 139 min.) / M. Gibson, 2016.

11. Jarhead (war drama film; 123 min.) / S. Mendes, 2005.

12. Lone Survivor (biographical military action film; $121 \mathrm{~min}$.) / M. Luttrell, P. Robinson, 2013.

13. Lester R.R. A Parametric Description of Modern Military Culture for Civilian Mental Health Practitioners to Better Serve Those Who Serve: a doctoral paper presented to the faculty of the graduate school of professional psychology office of graduate studies university of denver Available at: http://digitalcommons. du.edu/cgi/viewcontent.cgi?article=1042\&context=capstone_masters (accessed 18.04.18).

14. Rahbek-Clemmensen J. et al. Conceptualizing the Civil-Military Gap: A Research Note / J. Rahbek-Clemmensen, E. M. Archer, J. Barr, A. Belkin, . Guerrero, C. Hall, K.E.0. Swain // Armed Forces \& Society, 2012. Vol. 38. No. 4. Pp. 669-678.

15. Saving Private Ryan (epic war film; 169 min.) / S. Spielberg, 1998.

16. Strom T.Q. et al. Cultural and ethical considerations when working with military personnel and veterans: A primer for VA training programs / T. Q. Strom, M. E. Gavian, E. Possis, J. Loughlin, T. Bui, E. Linardatos, J. Leskela, \& W. Seigel // Training and Education in Professional Psychology, 2012, vol.6, issue 2, pp. 67-75.

17. The Hurt Locker (war drama film; $138 \mathrm{~min}$.) / K. Bigelow, 2008.

18. We were Soldiers (war drama film; 138 min.) / M. Gibson, 2002.

( Р.Романов Александр Сергеевич (research2021@mail.ru), Балканов Илья Владимирович.

Журнал «Современная наука: актуальные проблемы теории и практики» 